\title{
Unilateral supernumerary kidney with contra lateral hydronephrosis - a rare case report
}

\author{
Ezzat Khalda, Gyanendra Narain Singh, Ashok Kumar Mandal, Rajiv
}

Kumar Department of Radiodiagnosis, Patna Medical College, Patna, India

\section{BRIEF REPORT}

Please cite this paper as: Khalda E, Singh GN, Mandal AK, and Kumar R. Unilateral supernumerary kidney with contra lateral hydronephrosis - a rare case report. AMJ 2014, 7, 5, 213-217. http://doi.org/10.21767/AMJ.2014.2019

Corresponding Author:

Dr Ezzat Khalda

Department of Radiodiagnosis

Patna Medical College

Patna-800004, Bihar, India

Email: ezzyhafiz@gmail.com

\section{ABSTRACT}

Supernumerary kidney is the rarest of all renal anomalies; fewer than 80 cases have been reported in the literature over the years. Supernumerary kidneys are most commonly located on the left side of the abdomen. Different pathologic conditions are reported to affect supernumerary kidneys and they may be associated with malformations of the upper urinary tract and genital tract. Because of their infrequent occurrence and reporting, they frequently cause diagnostic challenges. Here we report a case in a 14-year-old male patient of unilateral supernumerary kidney on the right side of the abdomen with multiple calculi, mal-rotation and a gross hydronephrotic left kidney.

\section{Key Words}

Hydronephrosis, renal anomalies, Supernumerary kidney.

\section{Implications for Practice:}

\section{What is known about this subject?}

Supernumerary kidney is the rarest of all renal anomalies. It results from the aberrant division of the nephrogenic cord into two metanephric blastemas; two kidneys then form in association with a partially or completely duplicated ureteral bud.

\section{What new information is offered in this study?}

Contrast-enhanced computed tomography revealed two separate functional right kidneys and a mal-rotated gross hydronephrotic left kidney in a 14-year-old male patient who presented with repeated attacks of urinary tract infections.

3. What are the implications for research, policy, or practice?

Supernumerary kidneys may be associated with different urogenital malformations and be the cause of high rate of complications, including malignant change.

\section{Background}

Supernumerary kidney is a rare congenital anomaly. It results from the aberrant division of the nephrogenic cord into two metanephric blastemas; two kidneys then form in association with a partially or completely duplicated ureteral bud. ${ }^{1}$ The true incidence of this anomaly cannot be calculated because of its infrequent occurrence, but to date approximately 80 cases have been reported in the literature. ${ }^{2}$ Because of the scarcity of reported cases and atypical presentation, they frequently causes diagnostic difficulties. $^{3}$

\section{Case details}

A 14-year-old male patient who presented with frequent attacks of acute left flank pain was referred to the radiodiagnosis department of our hospital for imaging studies. General examination revealed a person of thin build and mild tachycardia (pulse 92/min). No other abnormality detected.

Past medical history revealed there were repeated attacks of urinary tract infections. There was no family history of renal disease or any other major illness.

Routine haematological and biochemical investigations were within normal limits except for a raised total leukocyte count. Ultrasonography of the abdomen showed left-sided gross hydronephrosis, which aroused the suspicion of supernumerary kidney on the contralateral side. CT scan of the abdomen without 
contrast showed left-sided gross hydronephrosis and two separate kidneys on the right side. Intravenous-contrast enhanced CT depicted two separate kidneys and a gross hydronephrotic left kidney. The cranially located right kidney measured $10.4 \times 3.7 \mathrm{~cm}$, and the caudally located right kidney measured $9.2 \times 4.5 \mathrm{~cm}$ with normal excretion of contrast. The left kidney measured $9.0 \times 3.2 \mathrm{~cm}$ with delayed excretion of contrast (Figure 1). The left kidney had a pelvi ureteral junction (PUJ) obstruction and marked rotational anomaly (Figure 2).

Figure 1: Coronal MIP reconstruction of contrast-enhanced computed tomography. 3D volume rendering showing gross hydronephrotic left kidney (big arrow) and two separate right kidneys (small arrows).

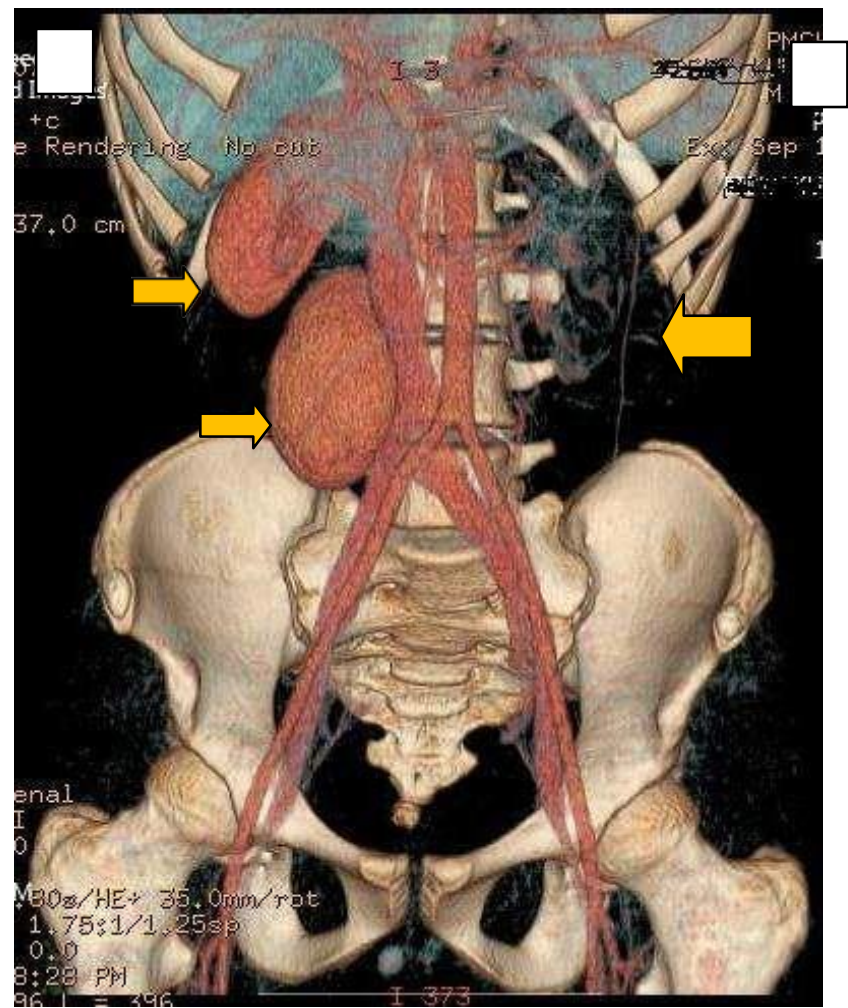

Figure 2: Axial contrast enhanced CT showing marked rotational anomaly of left hydronephrotic kidney.

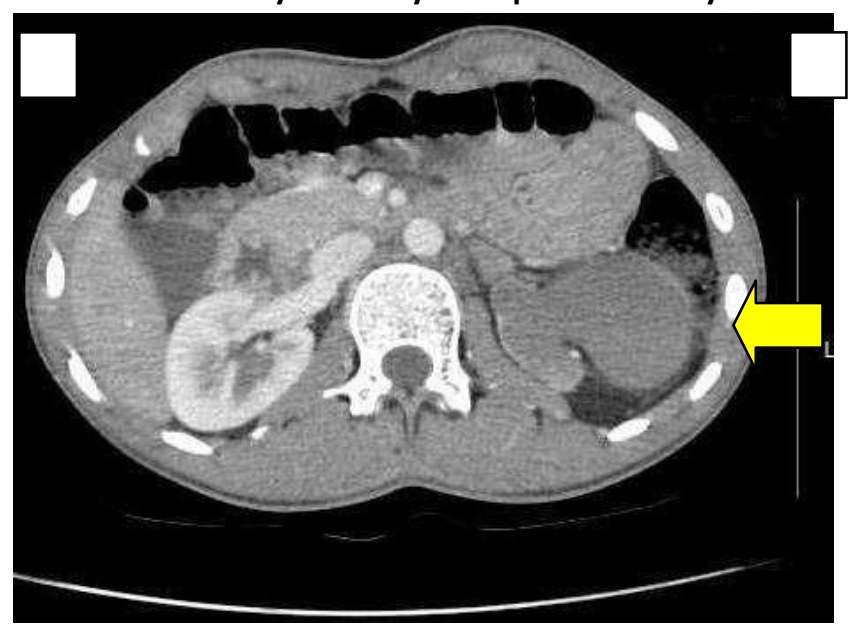

The two right kidneys were separate and inferiorly located kidney was slightly smaller than superiorly located kidney and had multiple calculi at its pelvicalyceal system (Figure 3).

Figure 3: Coronal MIP reconstruction of contrastenhanced CT shows inferiorly located right inferior supernumerary kidney had multiple calculi at pelvicalyceal system (arrow).

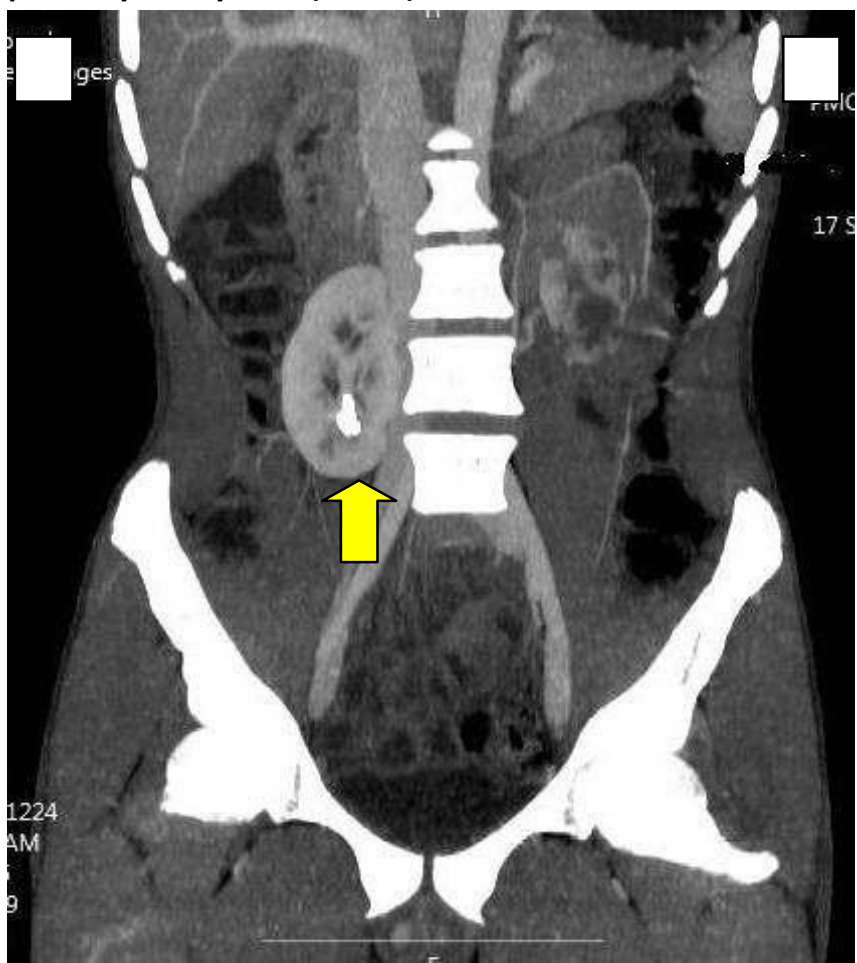

Figure 4(A-D): Axial contrast-enhanced CT reveals the artery of the right cranial kidney originating from the abdominal aorta (small arrow) and marked rotational anomaly of left hydronephrotic kidney

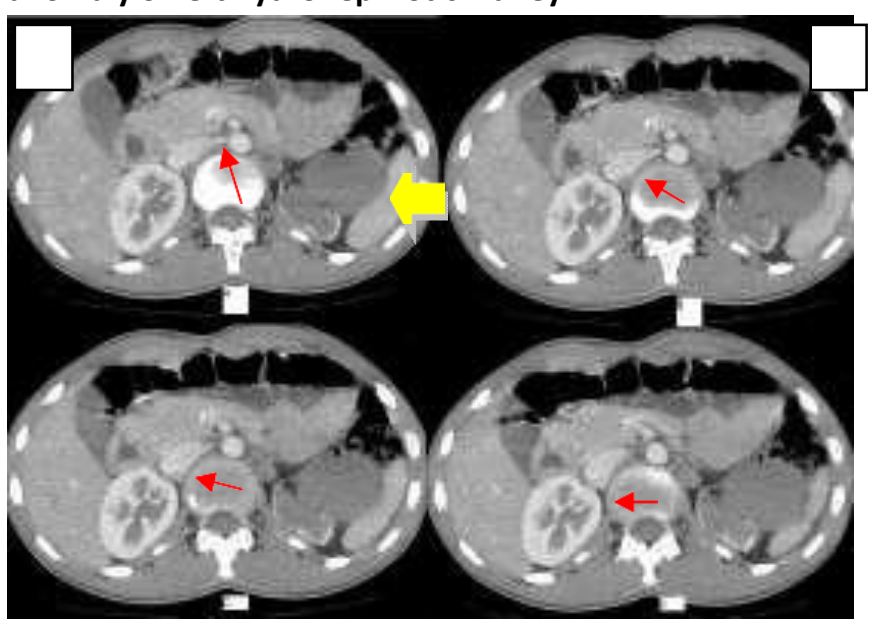

Two distinct main renal arteries supplied the two separate kidneys. The cranially placed kidney received its arterial supply from a branch of the abdominal aorta (Figure 4). The caudally placed kidney received its arterial supply from a branch of the right common iliac artery (Figure 5). 
Figure 5: Coronal MIP reconstruction of contrast-enhanced CT shows the artery of the right supernumerary kidney had its origin from the right common iliac artery

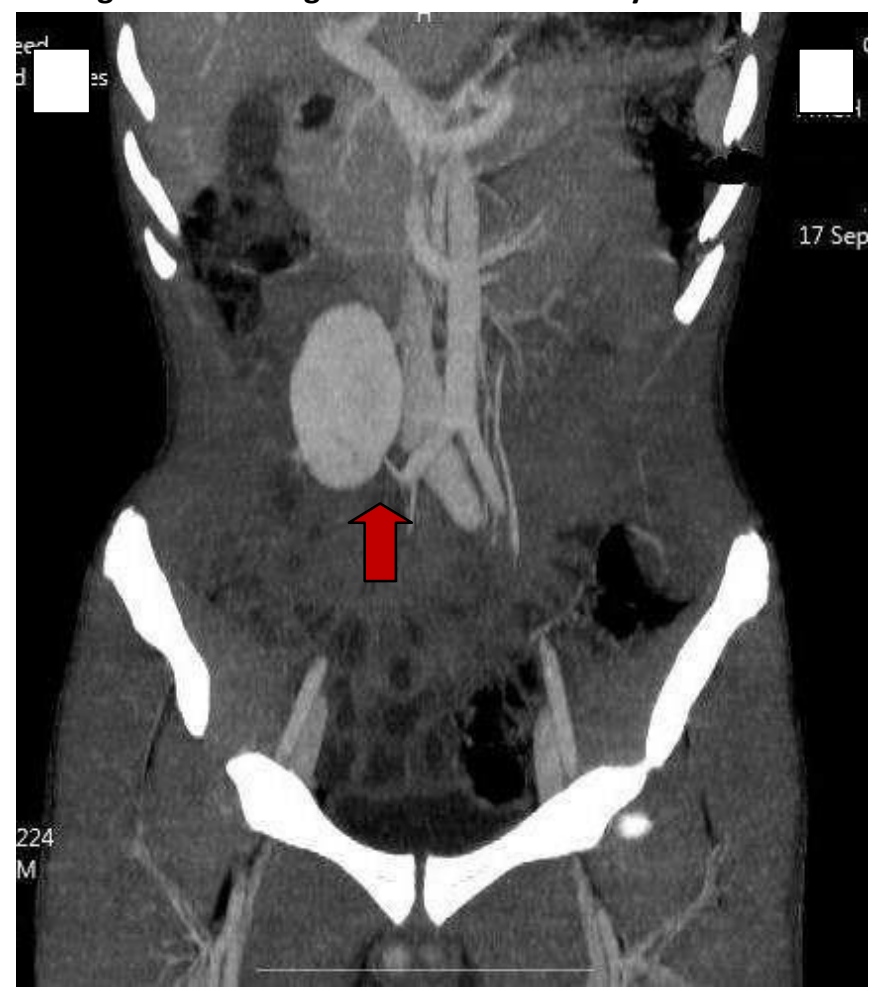

Figure 6: Intravenous pyelogram showing upper ureters of both the right kidneys joined to form a common ureter (bifid ureter)

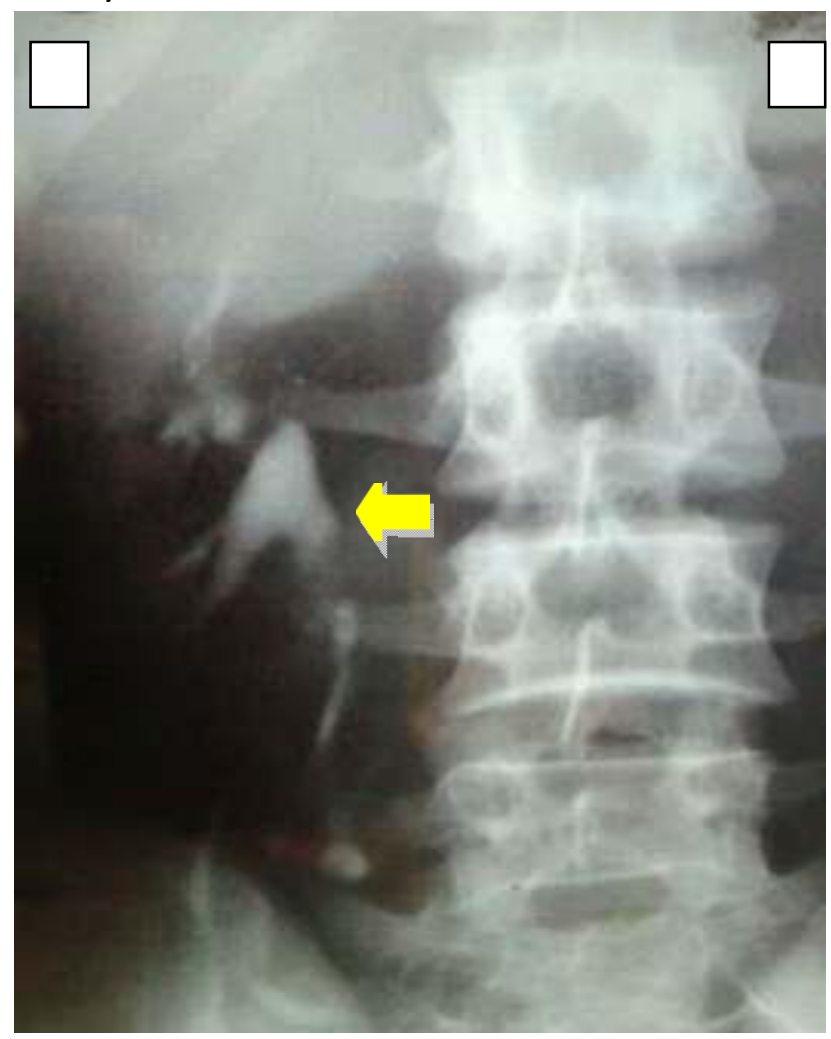

An IVP was also carried out which showed upper ureters of both the kidneys joined to form a common ureter at the level of ureteropelvic junction of the lower kidney in the right side (Figure 6).

\section{Discussion}

Many hypotheses have been proposed about embryological processes, which lead to supernumerary kidneys, but none has been proved. Most theories propose premature division of ureteric buds or coming off of two buds from the Wolffian duct. ${ }^{4}$

A supernumerary kidney may be of same size as, larger than, or more commonly smaller than the usual kidney. It functions normally, possess a normal shape and capsule, and is either not attached to or loosely attached to the normal kidney but in an abnormal location. Most commonly they are located on the left side of the abdomen, caudal to normal kidney. ${ }^{3}$ However, the position of the extra kidney has been quite variable from case to case. It may be located in front, below, above, or behind the usual kidney. ${ }^{5,6}$ They can also be found in the iliac region or anterior to the sacral promontory. ${ }^{7}$ Kusuma et al. reported a case of supernumerary kidney which presented as indirect inguinal hernia. ${ }^{8}$ In our case, the supernumerary kidney was located on the right flank just below the normal kidney approximately with the same size and was separated from the normal kidney.

The rare supernumerary kidney may be distinguished from the common fused duplex renal system by a fundamental difference in embryogenesis. In fused duplex bifid kidneys with bifid ureters one bud bifurcates and each branch penetrates independently the composite metanephric mass of mesenchyme. When two buds arise separately from the Wolffian duct and penetrate the same metanephric mass two independent renal urinary collecting systems form but the parenchymas remain fused. In supernumerary kidneys with bifid ureters one bud bifurcates and each branch penetrates independently a metanephric mass, which develops into separate reniform kidneys. The supernumerary kidney is thought to be an accessory organ with a separate arterial supply, venous drainage, collecting system, and distinct encapsulated tissue. ${ }^{1}$ It may have either a separate ureter or more commonly bifid ureters (53 per cent). ${ }^{5}$ In our case the ureters were bifid. Rarely the ureter of the supernumerary kidney may have an ectopic opening. ${ }^{1}$

Symptoms have been noted in approximately two-thirds of the reported cases of supernumerary kidney. ${ }^{9}$ When symptomatic they may cause fever, pain, or palpable abdominal mass. ${ }^{3,6}$ For the diagnosis of supernumerary kidney IVP, ultrasonography, nuclear scintigraphy, CT, and MRI may be used. ${ }^{7,10}$ 
As supernumerary kidneys are usually smaller and some time may have reduced function, so its evaluation by excretory urograms is often unsatisfactory. Conrad et al. (1987) described that Dimercaptosuccinic acid (DMSA) scintigraphic examination gives a better imaging and functional assessment of supernumerary kidney in compared to excretory urograms. ${ }^{10}$ In our case, CT was diagnostic and clearly demonstrated two separate kidney in the right side. CT angiography allows us to understand the complex arterial anatomy of kidneys and to detect the renal arteries arising both from the aorta and common iliac arteries non-invasively. Pathologic conditions reported to affect supernumerary kidneys include hydronephrosis, pyonephrosis, pyelonephritis, cysts, calculi, carcinoma, papillary cystadenoma, and Wilms' tumour. ${ }^{1,9,11}$ In our case, the supernumerary kidney had multiple calculi in its pelvicalyceal system.

Supernumerary kidneys may be associated with urogenital malformations like horseshoe kidney, ectopic ureteral opening, vaginal atresia, double collecting system, aortic coarctation, nipple anomalies, duplication of the female urethra, and duplication of the penis. ${ }^{1,9,11-12}$ In our case, contra-lateral kidney was grossly malrotated and there was pelvic ureteric junction obstruction with gross hydronephrosis.

Long-term follow up is recommended for asymptomatic cases of supernumerary kidney because of high rate of occurrence of complications and reported malignant change. ${ }^{13}$ The modality and time interval of follow-up has not yet been reported. But review of literature suggests yearly sonography in asymptomatic cases and sonography with IVP are usually sufficient in symptomatic cases. ${ }^{14}$ Appropriate surgical procedure may be needed when supernumerary kidneys are affected by pathologic conditions and become symptomatic. ${ }^{15}$

Although in the literature about 80 cases have been reported, our case is interesting and different from others in that it demonstrated multiple renal calculi in the supernumerary kidney and malrotated gross hydronephrotic left kidney with congenital PUJ obstruction.

\section{Conclusion}

Supernumerary kidney is a very rare congenital renal anomaly and may be associated with different urogenital malformations. Because of the potentially high rate of complication, including malignancy, diagnosis is very important. However, because of their infrequent occurrence diagnosis may be challenging.

\section{References}

1. Tada Y, Kokado V, Hashinaka Y. Free supernumerary kidney: A case report and review. J Urol 1981;126:231-32.

2. Ramasamy S, Paramasivam J, Janardhanam K. Supernumerary kidney presenting as pyonephrosis. Indian J Urol 2009;25:389-91.

3. Bernik TR, Ravnic DJ, Bernik SF, Wallack MK Ectopic supernumerary kidney, a cause of para-aortic mass: case report and review. Am Surg 2001:67:657-59.

4. Mutlubas F, Mir S, Sevinc E, Turker O. Unilateral double kidney with contralateral supernumerary kidney which found incidentally. Ege Journal of Medicine 2007;46:171-3.

5. Carlson HE. Supernumerary kidney: a summary of 51 reported cases. J Urol 1950;64:224-29.

6. Koureas AP, Panourgias EC, Gouliamos AD, Trakadas SJ, Vlahos LJ. Imaging of a supernumerary kidney. Eur Radiol 2000;10:1722-23.

7. Flyer MA, Haller JO, Feld M, Kantor A. Ectopic supernumerary kidney: Another cause of a pelvic mass. Abdom Imaging, 1994;19:374-5.

8. Kusuma V, Hemalata $M$, Suguna B V. Ectopic supernumerary kidney presenting as inguinal hernia. J Clin Pathol 2005; 58:446-8.

9. Wu JP, Garcia J. Supernumary kidney with Wilms' tumor. Wis Med J 1971;70:211-6.

10. Conrad RG, Loes DJ. Ectopic supernumerary kidney functional assessment using radionuclide imaging. Clin Nuc Med 1987;4:253-7.

11. Eberle J, Schwarz E, Abbrederis K Kidney calculus episode in a supernumerary 3rd kidney. Urologe $A$ 2002;41:362-3.

12. Antony J. Complete duplication of female urethra with vaginal atresia and supernumerary kidney. J Urol 1977;118:877-8.

13. Upsdell SM. Supernumerary kidney. $\mathrm{Br} J$ Urol 1989;64:65.

14. Oto A, Kerimoglu U, Eskicorapci S, Hazirolan T, Tekgul S. Bilateral supernumerary kidney: imaging findings. JBR-BTR 2002;85:300-03.

15. Ozturk E, Yaman I, Bayarogullari H, Guzelmansur I. A rare anomaly presented with symptoms of acute abdomen: a third kidney located at right iliac fossa. Ulus Travma Acil Cerrahi Derg 2007;13:67-9.

\section{PEER REVIEW}

Not commissioned. Externally peer reviewed. 


\section{CONFLICTS OF INTEREST}

The authors declare that they have no competing interests.

\section{PATIENT CONSENT}

The authors, Ezzat Khalda, GN Singh, Ashok Kumar Mandal and Rajiv Kumar declare that:

1. They have obtained written, informed consent for the publication of the details relating to the patient(s) in this report.

2. All possible steps have been taken to safeguard the identity of the patient(s).

3. This submission is compliant with the requirements of local research ethics committees. 